\title{
Pathways of participation in paid and unpaid work in mid to later life in the United Kingdom
}

\author{
Lawrence B. Sacco ${ }^{1 \star}$ (D), Laurie M. Corna ${ }^{2}$ (D), Debora Price ${ }^{3}$ (D) and Karen Glaser ${ }^{4}$ (D) \\ ${ }^{1}$ Stress Research Institute, Department of Psychology, Stockholm University, Stockholm, Sweden, ${ }^{2}$ Centre \\ of Competence on Ageing, Department of Business Economics, Health \& Social Care, University of \\ Applied Sciences \& Arts of Southern Switzerland, Manno, Switzerland, ${ }^{3}$ Manchester Institute for \\ Collaborative Research on Ageing, University of Manchester, Manchester, UK and ${ }^{4}$ Institute of \\ Gerontology, Department of Global Health and Social Medicine, King's College London, London, UK \\ *Corresponding author. Email: lawrence.sacco@su.se
}

(Accepted 16 September 2021)

\begin{abstract}
Policy responses to population ageing have focused on lengthening working lives, overlooking inequalities in older adults' participation in unpaid activities. This paper examines participation in paid and unpaid activities between the ages of 55 and 70 to answer two questions: how do people navigate pathways of paid work, informal care, volunteering, civic participation and housework in mid to later life?; and how do these pathways relate to gender, socio-economic and health inequalities? Two-staged latent class analysis was used to identify activity pathways using data from the British Household Panel Survey (1996-2008). Multinomial logistic models assessed associations between latent pathways and socio-demographic and health characteristics. Three pathways were observed: fulltime work to low activity (49\%), part-time and in-home work (34\%) and multiple activities (16\%). Aside from retirement from full-time work, the pathways of participation in paid and unpaid activities were characterised by continuity; substitution between different forms of paid and unpaid work was not observed. Participation in multiple paid and unpaid activities was more common for respondents in better health and of higher socio-economic status. Since the promotion of paid work and volunteering in later life may mainly benefit individuals in advantaged circumstances, policies should avoid taking a blanket approach to encouraging participation in multiple activities, a key component of active ageing.
\end{abstract}

Keywords: active ageing; role theory; multiple activities; volunteer work; housework; informal care-giving; employment; cumulative inequality

\section{Introduction}

Concerns about population ageing have led many countries to implement policies to lengthen working lives. The active ageing framework developed by the World Health Organization (2002) promotes being active in both paid and unpaid stricted re-use, distribution and reproduction, provided the original article is properly cited. 
forms of work, with the aim of improving population health. In practice, the active ageing concept has disproportionately focused on paid work and extending working lives (Boudiny, 2013; Foster and Walker, 2015), overlooking unpaid activities, such as volunteering, housework and informal care. The implications of extended working lives policies for older adults' contributions to unpaid work are often overlooked. Paid employment can restrict an individual's participation in unpaid activities, such as volunteering or informal care-giving, due to limits on time and energy. The extent to which participation in various activities in later life is socially patterned has also been overlooked. Older adults are an extremely heterogeneous group, in terms of socio-demographics and health, and do not all have the same opportunities, resources or desire to become 'active agers' in the same way.

At present, our understanding of how individuals combine paid and unpaid work in later life is limited. Previous research has often studied how participation in one domain affects another at one point in time (e.g. how care-giving affects paid work), without considering participation in multiple activities over time in a holistic way. Moreover, we know relatively little about how involvement in paid and unpaid activities is socially patterned or related to health. Indeed, policies affecting retirement age may reinforce existing (dis)advantages in the years leading up to and following State Pension age.

The aim of this paper is to examine the interplay between multiple activities in the years preceding and following the State Pension age in the United Kingdom (UK) by showing pathways of participation in paid and unpaid activities from ages 55 to 70 . Activity pathways are examined in relation to socio-demographic and health characteristics. The findings provide valuable evidence for understanding how longer working lives influence involvement in unpaid forms of work and provide insight into inequalities in participation in paid and unpaid work in later life.

\section{Paid and unpaid work: complementary or competing activities?}

\section{Role theory and multiple activities in later life}

While maintaining social roles benefits individuals by integrating them in society (Parsons, 1951), role strain theory suggests that holding multiple roles may lead to conflicts, as individuals can struggle to reconcile the various obligations arising from their roles (Goode, 1960). As a result of this tension, involvement in a given role may be reduced or dropped entirely. For example, care-giving duties for an ill or disabled relative may generate conflict by competing for the time that otherwise would be dedicated to paid employment. By contrast, role enhancement, or role accumulation, posits that the accumulation of multiple roles benefits individuals through the acquisition of social status, prestige, resources and personal growth (Sieber, 1974).

These theoretical underpinnings provided by role theory are relevant for understanding patterns of participation in multiple activities in mid to later life, as individuals may rearrange their commitments to adapt to changes that are common in this lifestage: retirement from paid work, onset of care-giving commitments to parents and/or spouses or partners, and, for some, declining health. Role substitution and role extension hypotheses have been used in empirical investigations concerning complementary and competitive activities in later life (Hank and Stuck, 2008). According to the role substitution hypothesis, undertaking a new activity can 
compensate for the loss of another role, e.g. a retiree may take up volunteering to compensate for their relinquished role as employee (Mutchler et al., 2003). According to the role extension hypothesis, participation in different roles is complementary, whereby engaging in a given role leads to a higher likelihood of engaging in a second one (Choi et al., 2007). For example, being in paid work may be conducive for volunteering as professional networks may increase the likelihood of coming into contact with volunteering opportunities (Wilson, 2000). Similarly, carers may be more likely to volunteer due to having contacts with social networks that provide opportunities for volunteer work (Burr et al., 2005; Strauss, 2021).

Overall, it is unclear whether there is role substitution or extension between paid work and unpaid activities in later life. As outlined in the following subsection, knowledge gaps limit our understanding of overall patterns of paid and unpaid activities in the years that precede and follow the State Pension age. First, previous studies have documented heterogeneous interrelationships between pairs of activities which appear to depend on the type and intensity of the involvement. Second, a large portion of previous evidence focused on only informal care and volunteering as unpaid forms of work, rarely considering other activities that have been shown to influence overall allocation of time, such as leisure activities and housework (Dosman et al., 2006; Fast et al., 2006; Dury et al., 2016). Third, the few studies that have examined latent patterns of paid and unpaid work are cross-sectional. Finally, few studies have evaluated how participation in multiple activities relates to demographic, socio-economic and health characteristics (Morrow-Howell et al., 2014; Mergenthaler et al., 2019).

\section{Existing evidence on participation in paid and unpaid work}

Previous evidence is mixed regarding the influence of paid work on participation in unpaid activities, as associations between different activities are heterogeneous. Informal care-giving, which is often an obligatory and inflexible activity, tends to compete with paid work (Carr et al., 2018; Kelle, 2020), as care-givers are more likely to retire from paid work (role substitution) (Dentinger and Clarkberg, 2002; Carr and Kail, 2012; Jacobs et al., 2014). Concerning volunteering, which is a discretionary activity as individuals generally can decide the extent and timing of their involvement, the evidence is conflicting. While some studies report no association between paid work and volunteering (Chambré, 1984; Herzog and Morgan, 1993; Caro and Bass, 1997; Choi, 2003; Carr and Kail, 2012), others report a higher probability of volunteering among older adults not in paid work (Mutchler et al., 2003; Dosman et al., 2006; Hank and Erlinghagen, 2009; van den Bogaard et al., 2014; Di Gessa and Grundy, 2017; Kobayashi et al., 2019); still others indicate that part-time employment may facilitate volunteering (Choi, 2003; Dosman et al., 2006; Carr and Kail, 2012).

While this growing body of literature has examined the interrelationships between paid and unpaid activities, most of these studies have investigated relationships only between two activities at a time (e.g. paid work and caring, or paid work and volunteering). The focus on pairs of activities is limiting as it does not adequately account for the complexity of experiences in the years preceding and 
following traditional retirement ages. In particular, the potential heterogeneity in overall patterns of paid and unpaid activities has been overlooked. Previous literature has acknowledged the complexity of later-life trajectories in paid work, as retirement has come to be viewed as a process with suggestions of fragmentation and differentiation of retirement trajectories in the population (Moen, 2003; Vickerstaff and Cox, 2005; Fasang, 2010; Calvo et al., 2017). However, only a few, mostly cross-sectional, studies have examined the heterogeneity present in patterns of participation in paid and unpaid activities (Burr et al., 2007; Fernandez-Ballesteros et al., 2011; Morrow-Howell et al., 2014; van der Horst et al., 2017b; Arpino and Bordone, 2018; Mergenthaler et al., 2019). As individuals transition in and out of multiple roles and activities over their lifecourse, a holistic approach to participation in multiple activities over time is needed.

Cross-sectional studies that used cluster methods provide nuanced snapshots of the heterogeneity of individuals' involvement in multiple activities in later life. These studies identified broadly similar groups across different samples: groups with overall low activity ('low-activity', 'family disengagers', 'the inactive'), groups mostly involved in home-based activities ('family helpers', 'in-home activities', 'home-maintainers'), highly active groups ('high activity', 'multiple-engagers', 'super-helpers', 'the active') and volunteering-oriented groups (Burr et al., 2007; Fernandez-Ballesteros et al., 2011; Morrow-Howell et al., 2014; Arpino and Bordone, 2018; Mergenthaler et al., 2019). While investigating distinct patterns of activities at single points in time, these studies cannot address how participation in paid and unpaid work develops over time. An exception is a noteworthy study that examined interrelationships between sequences of paid work, care-giving and volunteering over a ten-year period, showing that, while different sub-groups were largely unrelated, volunteering and part-time paid work seemed complementary (van der Horst et al., 2017b).

The primary aim of this study is to examine patterns of participation in paid work and unpaid activities in mid to later life as they evolve over time, using data from the British Household Panel Survey (BHPS). We address the following research question:

- How do individuals combine multiple activities (paid work, volunteering, informal care, housework and civic participation) over time, from age 55 to 70 ?

We extend previous cross-sectional research by incorporating a longitudinal approach, two-staged latent class analysis (LCA), which allows the examination of how latent configurations of activities at each age are linked into distinct agegraded activity pathways (Macmillan and Eliason, 2003; Corna and Sacker, 2013). As well as examining employment, volunteering and informal care-giving, we consider housework and civic participation, which have been shown to be relevant when examining the latent structure of activities in later life (Burr et al., 2007; Mergenthaler et al., 2019).

\section{Patterns of participation in activities and cumulative inequality}

Beyond understanding how older adults combine various paid and unpaid activities over time, understanding the social patterning of activities is crucial for ensuring 
that recent policy pushes towards longer working lives and active ageing do not disproportionately advantage some, while disadvantaging others. Relevant here is the notion of cumulative inequality: a process whereby disadvantaged individuals are more exposed to cumulative risks and advantaged individuals to cumulative opportunities (Ferraro and Shippee, 2009). Cumulative inequality provides a framework that can complement role theory by underscoring how (dis)advantageous circumstances shape opportunities for participation in paid and unpaid work in mid to later life. Individuals in a position of relative advantage (e.g. in higher socioeconomic groups and better health) may have a wider choice with respect to their involvement in paid and unpaid activities in later life (O'Rand, 1996; Gonzales et al., 2015). For example, those with fewer socio-economic resources may need to work for longer despite not having access to suitable job opportunities, or they may be more likely to provide long hours of informal care, given restricted access to social care services and lifetime histories of providing care.

Previous cross-sectional research provides some insight into this issue: women are often over-represented in groups characterised by family care, the same groups which are also more likely to be economically vulnerable (Morrow-Howell et al., 2014; Mergenthaler et al., 2019). Groups characterised by volunteering or involvement in several activities tend to have higher education and better health (Morrow-Howell et al., 2014; Mergenthaler et al., 2019). From a policy perspective, understanding who is most likely to follow any given activity pathway over time may offer insight into how opportunities and resources for all older adults could be fostered.

The secondary aim of this study is to evaluate how activity pathways are socially patterned and associated with health, in order to gain an insight into social and health inequalities. We address the following research question:

- How do activity pathways relate to gender, socio-economic and health inequalities?

Consistent with cumulative inequality theory, we anticipated that higher socioeconomic position would lead to participation in discretionary unpaid activities (volunteering and civic participation) and paid work, since involvement in these activities in later life is facilitated by better health and higher human capital (Wilson, 2000; Li and Ferraro, 2006). Conversely, we expected that less-advantaged circumstances would be more likely to be associated with pathways that are characterised by care-giving and lower levels of participation in paid and unpaid activities.

\section{Design and methods}

\section{Data}

This study used data from seven waves of the BHPS encompassing the period 19962008 (University of Essex, Institute for Social and Economic Research, 2018). The BHPS collected individual-level data annually from households in the UK from 1991 to 2008, including detailed information on unpaid activities. From 2009, the BHPS sample became part of the larger UK Household Longitudinal Study (UKHLS). However, information collected as part of the UKHLS was not used in 
this study due to changes in the questions concerning volunteering and civic participation. In the first wave of the BHPS, 10,264 individuals (95\% of eligible adults over the age of 16) in 5,538 households were interviewed. All members of households are interviewed, with new household members added to the samples during subsequent waves. The first wave of the BHPS, in 1991, achieved a household-level response rate of 69 per cent. The wave-on-wave response rate remained consistent for all 18 waves, ranging from a minimum of 86 per cent in Wave 2 to a maximum of 95 per cent in Wave 18 (Taylor, 2010).

Data for this study were drawn from seven waves of the BHPS collected every other year from 1996 to 2008, as respondents were asked about volunteering and civic participation only in these waves. Participants were included if they provided information about their involvement in paid and unpaid work in at least one wave. Observations were included in the analytical sample only when eligible respondents were aged 55-70. Observations from proxy and telephone respondents were excluded. The final analytical sample contained 6,068 respondents who provided 18,600 observations in total, with an average of 3.1 responses each throughout the observation period. The longitudinal data were restructured by age for the two-staged LCA, reflecting the accelerated longitudinal design.

\section{Measures}

\section{Paid and unpaid activities}

Since variables were available biennially, we created indicators for paid work, caregiving, volunteering, civic participation and housework over pairs of ages (i.e. 5556 to $69-70$ ). The measure of paid work distinguished three categories: $0=$ not in paid work; 1 = part-time paid work; 2 = full-time paid work. Respondents were asked how many hours they were expected to work in a normal week. Those who reported at least 30 hours per week (including overtime), were categorised as full-time workers. This cut-off has been used in previous relevant studies (Henz, 2004; Glaser et al., 2006; Carr et al., 2018).

Two items from the interview were used to measure informal (unpaid) care provision according to location. Participants were first asked if they live with someone who is a 'sick, handicapped or elderly person whom you look after or give special help to'; then they were asked an equivalent question for care-receivers not living in the same household. Three categories were used: 0 $=$ not providing care; 1 = providing extra-residential informal care; $2=$ providing co-residential informal care. A small proportion of respondents reported providing both extra- and co-residential care (approximately $1.5 \%$ at each age). To preserve model parsimony of LCA, these were categorised as providing co-residential care, as has been done in previous research (Michaud et al., 2010), given that co-residential care-giving is likely to be a more intense and time-demanding activity compared to extra-residential care.

For housework, participants were asked 'About how many hours do you spend on housework in an average week, such as time spent cooking, cleaning and doing the laundry'. After inspection of the distribution, the variable for housework was trichotomised: $0=0$ to 10 hours per week; $1=$ more than 10 hours per week but less than $20 ; 2=20$ or more hours per week. 
Respondents were asked two separate questions about volunteering ('how frequently you ... do unpaid voluntary work') and civic participation ('how frequently you ... attend meetings for local groups or voluntary organisations'). Sociological research distinguishes these two activities as qualitatively different, given that the former produces goods or services while the latter consumes the services provided by voluntary organisations (Chambré, 1984; Wilson, 2000). The wording of the questions aids this distinction, as the question for volunteering emphasises the active nature of the task, while the one about civic participation captures more passive involvement. Binary indicators for volunteering and engaging in civic participation on a regular basis were created $(0=$ never or almost never/once a year or less/ several times a year; $1=$ at least monthly/at least weekly).

\section{Demographic, socio-economic and health variables}

Baseline socio-demographic and health variables, measured at first observation between the ages of 55 and 70, were included to assess the factors associated with each pathway. Regression analyses were stratified by gender. Birth cohort was recoded into four categories: respondents born in 1925-1929 = 0, 1930-1939 $=1,1940-1949=2$ and $1950-1953=3$. The marital status measure distinguished those who are married or co-habiting $=0$, from those who are divorced $=1$, widowed $=2$ and never married $=3$. Two binary variables were used to define parenthood. The first one distinguished respondents who had one or more children during their lifetime $=1$ from those who had none $=0$. The second identified respondents who lived in the same household with one or more child (natural, adopted or stepchildren) under the age of $16=1$ from those who did not $=0$.

Participants' highest level of education was recoded into three categories: high/ post-secondary education (higher degree, teaching and other higher qualifications, nursing diploma); medium (GCE A/O levels or equivalents, commercial qualifications, CSE grades 2-5, apprenticeship, other qualification); and no qualifications. Housing tenure was trichotomised to include: $0=$ outright home-owners, $1=$ homeowners with a mortgage, 2 = renters. Information on total household income in the month before the interview was utilised to create an equivalised measure of net household income divided into quintiles. The square root of household size was used as the equivalence scale (Levy and Jenkins, 2012). Subjective financial situation was assessed through a question asking how well one is managing finances and recoded into a binary indicator $(0=$ living comfortably/doing alright; $1=$ just about getting by/finding it quite difficult/finding it very difficult).

Information about self-rated health was available, although options were slightly different for the ninth wave of the BHPS. Therefore, the self-rated health variable was dichotomised into: $0=$ excellent/very good/good; $1=$ fair/poor/very poor. A binary variable of chronic health was derived from a question asking respondents whether they suffer from any health problems or disabilities, including arthritis, visual and hearing impairments, heart problems and diabetes. Those reporting any of these health problems or disabilities were categorised as having a chronic health problem. The 12-item General Health Questionnaire (GHQ) score, ranging from 0 to 36 , with higher scores indicating worse mental health, was used as a continuous variable (Goldberg and Williams, 1988). 


\section{Analytic approach: two-staged LCA}

We used two-staged LCA, which is an extension of the basic LCA modelling by combining results from multiple cross-sectional LCAs into a longitudinal approach (Macmillan and Eliason, 2003). In the first stage, cross-sectional LCA models were run for each age, yielding latent variables for the unobserved configurations of activities at ages 55-56, 56-57, .., 69-70 (Figure 1). In the second stage, a longitudinal LCA model connected the activities configurations from the first stage to identify the latent pathways of activities in mid to later life (Figure 1). Finally, multivariate multinomial logistic regression models were run to assess the association of demographic, socio-economic and health characteristics with the latent activity pathways.

As there is no single accepted fit statistic for choosing the optimal number of classes in LCA, several fit statistics and indices were used: the Lo-Mendell Rubin likelihood ratio test (LMR-LRT), the Akaike Information Criterion (AIC), the Bayesian Information Criterion (BIC), the sample size-adjusted BIC (SABIC) and the entropy index. The LMR-LRT tests the fit of nested LCA models, indicating whether a model with $k$ number of classes is preferred to one with $k-1$ classes (Asparouhov and Muthén, 2012). The AIC, BIC and SABIC are parsimony indices, where lower values indicate better fit (scree plots were used to observe when an index plateaued) (Tein et al., 2013). The entropy index provides an indication of the quality of the classification. Although there are no established clear cut-offs, entropy values above 0.80 are considered to be highly discriminant (Tein et al., 2013). When disagreement among indices and model fit statistics occurred, we also examined the proportion of individuals assigned to each class and the plausibility of the conditional probabilities (see Tables A.1 and A.2 in the online supplementary material). LCA models with classes smaller than 5 per cent were generally avoided as a rule of thumb.

Stata version 15.1 (StataCorp, 2017) was used for data management and Mplus version 8.4 (Muthén and Muthén, 2012) was used to run the LCA models and the multinomial logistic regressions. The two-staged LCA and the multinomial regression were run using full-information maximum likelihood (FIML) as the estimation procedure. This method conveniently allows for the use of all available data and is robust to the missing at random assumption (MAR) (Allison, 2012).

\section{Results}

\section{Descriptive statistics}

In total 6,068 individuals ( $46 \%$ men and $54 \%$ women) were included in the sample for the two-staged LCA. Table 1 shows the prevalence of activities by age. As anticipated, the prevalence of participation in full-time paid work dropped substantially with age, declining from 51 per cent at ages 55-56 to 2 per cent at ages 69-70. The percentage of part-time paid work declined less steeply and at later ages compared to full-time work, dropping from 18 per cent at ages 57-58 to 6 per cent at ages 6970. The prevalence of providing extra-residential informal care dropped gradually from 18 per cent at ages 55-56 to 11 per cent at ages 69-70, while co-residential care remained broadly constant, between 8.5 and 10 per cent. Prevalence of 

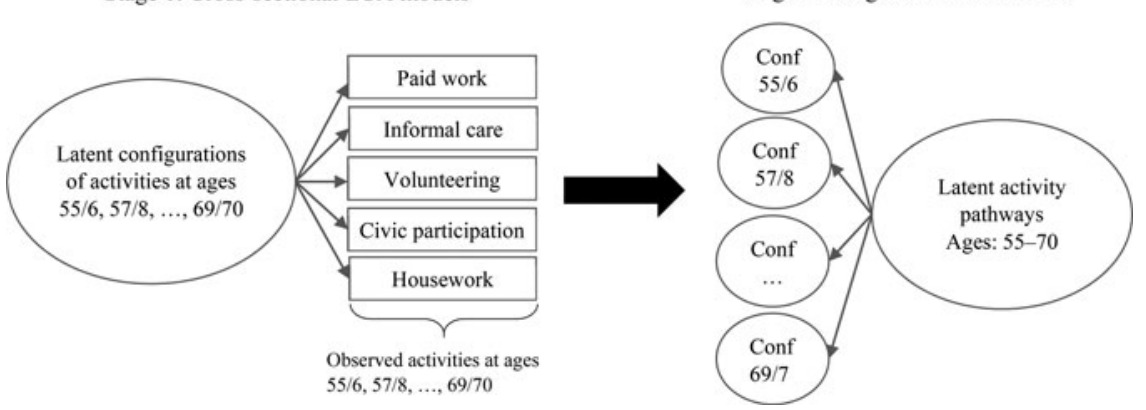

Figure 1. Two-staged latent class analysis (LCA) analytical strategy. Note: Conf: configuration.

volunteering increased when respondents were in their sixties, while civic participation became progressively more common after ages 57-58. A greater number of hours of housework was more common with increasing age: the prevalence of doing ten or fewer hours of housework per week decreased from ages 57-58 $(58 \%)$ to $69-70(54 \%)$, while the prevalence of doing 20 or more hours increased between ages $59-60(15 \%)$ and 63-64 (19\%).

\section{Mid- to later-life pathways of paid and unpaid activities}

First-stage LCA: configurations for each age group

Cross-sectional LCA models were applied at each age in the first stage. Table 2 shows the fit statistics used to assess model fit (the best fitting LCA models are in bold). At ages 55-56, the four-class solution was selected because the LMR-LRT was strongly significant; the AIC, BIC and SABIC were considerably lower than in the three-class solution and the entropy index was high (0.75). A four-class solution was preferred at ages 57-58 for the same reasons. At ages 5960 the three-class solution was preferred as the parsimony indices and the LMR-LRT favoured this configuration, as well as model interpretation of the conditional probabilities suggesting that the addition of a fourth class would have added little to our understanding. The four-class solution was composed of a small group (less than 5\%). Similar decision making was applied to select the appropriate LCA model at all ages.

Variations in the optimal number of classes at each age may reflect variation in paid and unpaid activities at each age. The conditional probabilities, which designate the likelihood of engaging in each paid and unpaid form of work, can be inspected to acquire a qualitative understanding of the latent classes (see Table A.1 in the online supplementary material). Configurations of activities at ages 55-57 to 61-62 were approximately similar: two larger classes (over 25\%), one characterised by full-time paid work, and the other by part-time paid work and housework; and one or two smaller classes (15\% or less) capturing those more likely to engage in volunteering and civic participation. The configurations at ages 63-64 to 69-70 (see Table A1.b in the online supplementary material) were somewhat different, as individuals who were previously classified in the full- 
Table 1. Descriptive prevalence of participation in each paid and unpaid activity by age

\begin{tabular}{|c|c|c|c|c|c|c|c|c|}
\hline & \multicolumn{8}{|c|}{ Age groups } \\
\hline & $55-56$ & $57-58$ & $59-60$ & $61-62$ & $63-64$ & $65-66$ & $67-68$ & $69-70$ \\
\hline & \multicolumn{8}{|c|}{ Percentages } \\
\hline \multicolumn{9}{|l|}{ Paid work: } \\
\hline Out of paid work & 31.8 & 37.2 & 47.3 & 60.2 & 70.3 & 84.2 & 89.1 & 92 \\
\hline Part-time & 17.6 & 17.7 & 16.2 & 13.5 & 11.3 & 9.2 & 7.1 & 6 \\
\hline Full-time & 50.6 & 45.1 & 36.5 & 26.3 & 18.5 & 6.6 & 3.8 & 2 \\
\hline \multicolumn{9}{|l|}{ Informal care: } \\
\hline No & 73.2 & 73.8 & 74.4 & 74.3 & 77.9 & 76.8 & 77.7 & 78.9 \\
\hline Extra-residential & 18.2 & 16.8 & 15.8 & 15.6 & 13.4 & 13.3 & 13.1 & 11.1 \\
\hline Co-residential & 8.5 & 9.3 & 9.8 & 10.1 & 8.6 & 9.9 & 9.2 & 10 \\
\hline \multicolumn{9}{|l|}{ Volunteering: } \\
\hline No & 87.3 & 85.8 & 86.2 & 83.6 & 82.8 & 81.3 & 81.2 & 82.2 \\
\hline Yes & 12.7 & 14.2 & 13.8 & 16.4 & 17.2 & 18.7 & 18.8 & 17.8 \\
\hline \multicolumn{9}{|l|}{ Civic participation: } \\
\hline No & 83.5 & 83.1 & 81.2 & 80.8 & 80.1 & 78.7 & 77 & 77.2 \\
\hline Yes & 16.5 & 16.9 & 18.8 & 19.2 & 19.9 & 21.3 & 23 & 22.8 \\
\hline \multicolumn{9}{|l|}{ Housework (hpw): } \\
\hline$\leqslant 10$ & 57.8 & 58 & 56.4 & 55.3 & 54.5 & 53 & 54.1 & 53.5 \\
\hline $11-20$ & 27.4 & 26.9 & 27.5 & 27.5 & 26.7 & 28.5 & 28.7 & 29.5 \\
\hline$>20$ & 14.8 & 15.1 & 16.2 & 17.1 & 18.9 & 18.5 & 17.2 & 17 \\
\hline Total & 2,820 & 2,679 & 2,557 & 2,388 & 2,185 & 2,082 & 2,002 & 1,887 \\
\hline
\end{tabular}

Notes: $\mathrm{N}=18,600$ pooled observations ( $N=6,068$ respondents). Percentage of individuals participating in each form of paid and unpaid work at each age. hpw: hours per week.

Source: British Household Panel Survey Waves 6, 8, 10, 12, 14, 16 and 18.

time paid work-oriented groups appeared to have shifted into 'low activity' groups with a low probability of engaging in both paid and unpaid activities (class 3 at age 65-66; class 3 at 67-68; class 2 at 69-70). However, the conditional probabilities from the first-stage LCA models represent cross-sectional snapshots of configurations of activities at each age, rather than longitudinal patterns. The second-stage longitudinal LCA facilitated the identification of longitudinal pathways.

\section{Second-stage LCA: mid- to later-life pathways}

Latent configurations of activities were used in a second-stage LCA to produce latent pathways. The three-class model was deemed to be the best solution (Table 3), which had a higher entropy index (0.69). Furthermore, the LMR-LRT was highly significant, indicating better fit than the two-class model, and the 
Table 2. Indices and statistics for the assessment of optimal model fit for the first-stage latent class analysis (LCA) models at each age

\begin{tabular}{|c|c|c|c|c|c|c|c|c|}
\hline Age & $\mathrm{N}$ & Latent class solution & AIC & $\mathrm{BIC}$ & SABIC & LMR-LRT & Entropy & Class proportions (\%) \\
\hline \multirow[t]{4}{*}{$55-56$} & 2,820 & 2 & 19,345 & 19,446 & 19,392 & $<0.001$ & 0.83 & $13 ; 87$ \\
\hline & & 3 & 18,926 & 19,080 & 18,998 & $<0.001$ & 0.75 & $8 ; 31 ; 61$ \\
\hline & & 4 & 18,874 & 19,082 & 18,971 & $<0.001$ & 0.75 & $29 ; 5 ; 12 ; 53$ \\
\hline & & 5 & 18,837 & 19,099 & 18,959 & 0.038 & 0.71 & $6 ; 16 ; 4 ; 51 ; 22$ \\
\hline \multirow[t]{4}{*}{$57-58$} & 2,679 & 2 & 18,641 & 18,741 & 18,687 & $<0.001$ & 0.77 & $15 ; 85$ \\
\hline & & 3 & 18,280 & 18,434 & 18,351 & $<0.001$ & 0.81 & $60 ; 11 ; 29$ \\
\hline & & 4 & 18,243 & 18,450 & 18,338 & $<0.001$ & 0.84 & $9 ; 57 ; 8 ; 27$ \\
\hline & & 5 & 18,230 & 18,489 & 18,350 & 0.88 & 0.7 & $22 ; 20 ; 6 ; 6 ; 47$ \\
\hline \multirow[t]{4}{*}{$59-60$} & 2,557 & 2 & 17,798 & 17,897 & 17,843 & $<0.001$ & 0.78 & $83 ; 17$ \\
\hline & & 3 & 17,483 & 17,635 & 17,552 & $<0.001$ & 0.65 & $54 ; 31 ; 15$ \\
\hline & & 4 & 17,461 & 17,666 & 17,555 & 0.187 & 0.7 & $4 ; 13 ; 52 ; 31$ \\
\hline & & 5 & 17,457 & 17,714 & 17,574 & 0.253 & 0.71 & $4 ; 5 ; 53 ; 25 ; 12$ \\
\hline \multirow[t]{4}{*}{$61-62$} & 2,388 & 2 & 16,658 & 16,756 & 16,702 & $<0.001$ & 0.68 & $22 ; 78$ \\
\hline & & 3 & 16,351 & 16,501 & 16,419 & $<0.001$ & 0.69 & $16 ; 34 ; 50$ \\
\hline & & 4 & 16,339 & 16,541 & 16,430 & 0.006 & 0.74 & $13 ; 7 ; 34 ; 46$ \\
\hline & & 5 & 16,338 & 16,592 & 16,453 & 0.608 & 0.69 & $14 ; 31 ; 7 ; 38 ; 9$ \\
\hline \multirow[t]{4}{*}{$63-64$} & 2,185 & 2 & 14,601 & 14,698 & 14,644 & $<0.001$ & 0.62 & $26 ; 74$ \\
\hline & & 3 & 14,401 & 14,549 & 14,466 & $<0.001$ & 0.75 & $15 ; 48 ; 38$ \\
\hline & & 4 & 14,386 & 14,585 & 14,474 & 0.079 & 0.76 & $8 ; 42 ; 35 ; 15$ \\
\hline & & 5 & 14,387 & 14,637 & 14,498 & 1 & 0.70 & $3 ; 14 ; 35 ; 8 ; 41$ \\
\hline
\end{tabular}


Table 3. Indices and statistics for the assessment of optimal model fit for the second-stage latent class analysis (LCA) models

\begin{tabular}{lcccccc}
\hline Classes & AIC & BIC & SABIC & LMR-LRT & Entropy & $\begin{array}{c}\text { Class proportions } \\
(\%)\end{array}$ \\
\hline 2 & 35,725 & 36,000 & 35,870 & $<0.001$ & 0.64 & $52 ; 48$ \\
\hline 3 & 33,409 & 33,825 & 33,628 & $<0.001$ & 0.69 & $49 ; 34 ; 16$ \\
\hline 4 & 33,044 & 33,601 & 33,338 & 0.878 & 0.69 & $48 ; 8 ; 32 ; 12$ \\
\hline 5 & 32,870 & 33,568 & 33,238 & 0.762 & 0.58 & $12 ; 7 ; 16 ; 40 ; 25$ \\
\hline
\end{tabular}

Notes: $\mathrm{N}=6,068$. Four LCA models, assessing two to five class solutions, were applied to assess the best fitting model for the latent activity pathways. The best fitting model is shown in bold. AIC: Akaike Information Criterion. BIC: Bayesian Information Criterion. SABIC: sample size-adjusted BIC. LMR-LRT: Lo-Mendell Rubin likelihood ratio test.

Source: British Household Panel Survey Waves 6, 8, 10, 12, 14, 16 and 18.

AIC, BIC and SABIC also seemed to favour this solution. This was confirmed in a scree plot, where these indices plateaued after the three-class solution.

Figure 2 shows the age-graded expected probabilities for each latent pathway, which were obtained by multiplying and summing the first- and second-stage conditional probabilities (see Table A.2 in the online supplementary material). The three pathways were referred to as: full-time (FT) work to low activity $(49 \%, \mathrm{~N}=$ 2,999), part-time (PT) and in-home work $(34 \%, \mathrm{~N}=2,073)$ and multiple activities $(16 \%, \mathrm{~N}=996)$. Relative to the other two pathways, the FT work to low activity pathway (Figure 2, leftmost column) was characterised by a higher probability of full-time paid work and a lower probability of engaging in all unpaid activities. The majority of participants classified by this pathway were men $(67.8 \%)$. The probability of participating in full-time paid work declined steadily in this subgroup in the early sixties, falling below 30 per cent by ages $63-64$. The probability of engaging in unpaid activities (volunteering, civic participation, informal care provision and housework for more than 20 weekly hours) remained below 20 per cent at all ages.

The second pathway, PT and in-home work (Figure 2, middle column), was mainly comprised of women (82.8\%), and captured the experiences of those who had an initial lower probability of working full-time, an initial higher probability of working part-time and spending more hours doing housework compared to the FT work to low activity pathway. In the PT and in-home work group the probability of working full-time was already low from ages 55-56 (29\%) compared to the other pathways, and declined steadily, dropping below 20 per cent by ages 61-62. By contrast, the probability of working part-time was higher from age 55 to 60 , especially in comparison to the FT work to low activity pathway. Another distinguishing feature of the PT and in-home work pathway relative to the other two sub-groups was the higher probability of doing housework and the slightly higher probability of providing co-residential care at all ages. The probabilities of volunteering and civic participation rose slightly from ages 59-60 to 65-66, as the probability of engaging in full-time paid work declined, possibly suggesting some role substitution for individuals classified in this pathway.

Those in the third pathway, multiple activities (Figure 2, rightmost column), were considerably more likely to engage in volunteering and civic participation, 

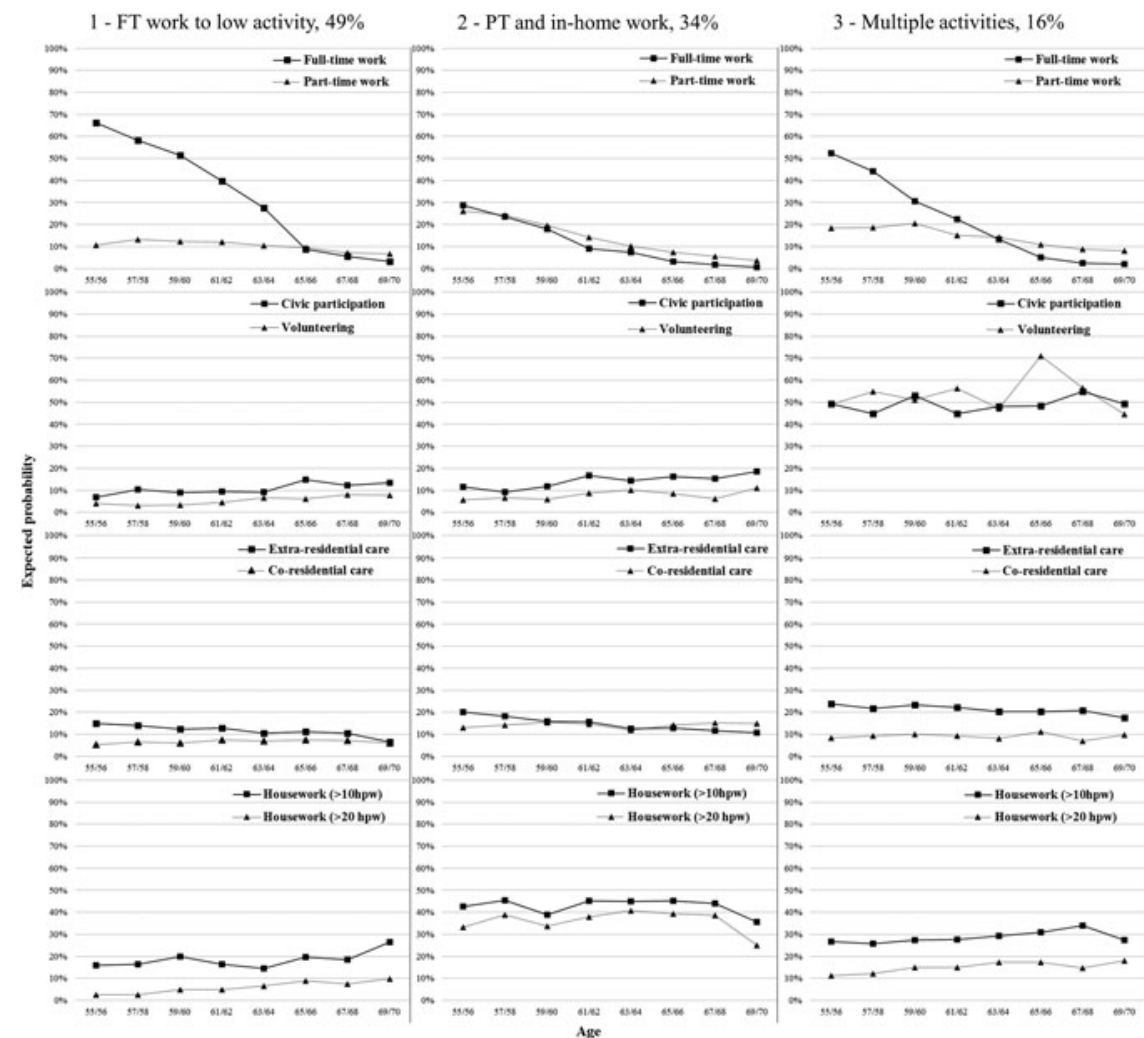

Figure 2. Probability of engaging in each paid and unpaid activity by age for each latent activity pathway. Notes: $\mathrm{N}=6,068$. The expected probabilities are calculated from the conditional probabilities yielded by the first- and second-stage latent class analysis models (see Table A.2 in the online supplementary material). Percentages at the top indicate proportion of the sample described by each pathway. FT: full-time. PT: part-time. hpw: hours per week. Source: British Household Panel Survey Waves 6, 8, 10, 12, 14, 16 and 18.

relative to the other two pathways. Of those in the third pathway, 59 per cent were women. The high probability of engaging in volunteering and civic participation was constant throughout, suggesting that changes in the probability of working fulltime that occurred during this period were not reflected in changes in these activities as role substitution or extension would have predicted. The probability of doing housework ( $>10$ and $>20$ hours per week) was lower than the PT and in-home work pathway and seemed to rise progressively over time. The probability of providing extra-residential informal care was higher compared to the second pathway.

Overall, results from the two-staged LCA showed the heterogeneity of paid and unpaid work patterns. The differences between the identified sub-groups emphasised that respondents were more oriented either towards full-time paid work, as exemplified by the FT work to low activity pathway, or towards a combination of unpaid activities with full-time or part-time paid work, as exemplified by the other two pathways. However, within each pathway, declines in the probability of 
being in paid work were not paralleled by increases in the probability of partaking in unpaid activities. Therefore, those individuals who were more likely to work in full-time employment for longer were also more likely to participate in fewer activities in their late sixties.

\section{The social and health patterning of pathways of paid and unpaid activities}

To understand the social patterning of the activity pathways, we examined their association with socio-demographic factors and health characteristics measured at each individual's baseline. The analysis was stratified by gender, given the stark differences in the proportion of men and women in each pathway. The most common gender-specific pathway was used as the reference category in the multinomial logistic regression models: FT work to low activity for men (Table 4) and PT and in-home work for women (Table 5).

Compared to men born in the 1940-49 cohort, cohorts born before 1940 had higher odds of being classified in the PT and in-home work pathway relative to the FT work to low activity (Table 4). Men who were divorced (odds ratio (OR) $=1.69,95 \%$ confidence interval $(\mathrm{CI})=1.2,2.37)$, widowed $(\mathrm{OR}=3.12, \mathrm{CI}=2.03$, $4.81)$ and never married $(\mathrm{OR}=2.41, \mathrm{CI}=1.71,3.4)$ were more likely than married men to follow the PT and in-home work pathway, though this relationship was attenuated in the multivariate model. Men who ever had a child were less likely to be classified in the PT and in-home work pathway $(\mathrm{OR}=0.55, \mathrm{CI}=0.42,0.72)$. Having lower socio-economic position increased the odds of following the PT and in-home work pathway, rather than the FT work to low activity pathway, among men. Men with lower education, renting rather than home-owning, in lower income quintiles and reporting worse financial circumstances had higher odds of being in the $P T$ and in-home work pathway. However, this relationship was attenuated in the multivariate model, especially for education, housing tenure and subjective finances. Conversely, being classified in the multiple activities pathway was associated with a more favourable socio-economic position and men in this sub-group were more likely to have post-secondary qualifications compared with no qualifications $(\mathrm{OR}=0.26, \mathrm{CI}=0.2,0.35)$ or intermediate education levels $(\mathrm{OR}=0.47, \mathrm{CI}=0.36$, 0.6). Reporting any chronic health condition, having worse GHQ scores and reporting worse self-rated health were associated with an increased odds of being in the PT and in-home work pathway. The odds of conforming to the multiple activities pathway was higher for those with better self-rated health and a better GHQ score. However, relationships for health variables became weaker in the multivariate models once birth cohort and socio-economic measures were added to the model.

Cohort differences predicted pathway membership among women in the bivariate models (Table 5). The 1950s cohort had raised odds of following the FT work to low activity pathway rather than the $P T$ and in-home work pathway $(\mathrm{OR}=1.4 \mathrm{CI}=$ $1.11,1.78)$ compared with women born in the 1940s. Women born in the 1930s had lower odds of belonging to the FT work to low activity pathway $(\mathrm{OR}=0.79$, $\mathrm{CI}=0.66,0.94)$. Divorced $(\mathrm{OR}=2.5, \mathrm{CI}=2,3.13)$, widowed $(\mathrm{OR}=1.38, \mathrm{CI}=$ $1.09,1.74)$ and never married $(\mathrm{OR}=2.99, \mathrm{CI}=2.06,4.33)$ women had a higher odds of being in the FT work to low activity pathway, and never married women were also more likely to be in the multiple activities pathway $(\mathrm{OR}=2.32, \mathrm{CI}=$ 
Table 4. Multinomial model of the association between activity pathways and individuals' baseline socio-demographic and health characteristics among men

\begin{tabular}{|c|c|c|c|c|c|c|c|c|}
\hline & \multicolumn{4}{|c|}{ Bivariate associations } & \multicolumn{4}{|c|}{ Multivariate model } \\
\hline & \multicolumn{2}{|c|}{$\begin{array}{l}\text { Path 2, PT and } \\
\text { in-home work }\end{array}$} & \multicolumn{2}{|c|}{$\begin{array}{c}\text { Path } 3 \text {, Multiple } \\
\text { activities }\end{array}$} & \multicolumn{2}{|c|}{$\begin{array}{l}\text { Path 2, PT and } \\
\text { in-home work }\end{array}$} & \multicolumn{2}{|c|}{$\begin{array}{c}\text { Path } 3 \text {, Multiple } \\
\text { activities }\end{array}$} \\
\hline & OR & $\mathrm{Cl}$ & OR & $\mathrm{Cl}$ & OR & $\mathrm{Cl}$ & OR & $\mathrm{Cl}$ \\
\hline \multicolumn{9}{|c|}{ Birth decade (Ref. 1940-1949): } \\
\hline $1925-1929$ & $3.6^{\star \star \star}$ & $2.47,5.26$ & 1.02 & $0.64,1.64$ & $2.72^{\star \star}$ & $1.79,4.13$ & 1.32 & $0.8,2.19$ \\
\hline 1930-1939 & $1.7^{\star \star}$ & $1.31,2.21$ & 1.01 & $0.8,1.29$ & $1.41^{\star}$ & $1.06,1.87$ & 1.18 & $0.9,1.53$ \\
\hline $1950-1953$ & 0.98 & $0.66,1.47$ & 1.08 & $0.79,1.49$ & 1.12 & $0.73,1.71$ & 0.88 & $0.63,1.22$ \\
\hline \multicolumn{9}{|c|}{ Marital status (Ref. Married or co-habiting): } \\
\hline Divorced & $1.69^{\star}$ & $1.2,2.37$ & $0.71^{\star}$ & $0.48,1.05$ & 1.38 & $0.95,2.01$ & 0.84 & $0.56,1.27$ \\
\hline Widowed & $3.12^{\star \star}$ & $2.03,4.81$ & 0.81 & $0.45,1.48$ & $2.37^{\star}$ & $1.5,3.75$ & 0.94 & $0.52,1.68$ \\
\hline Never married & $2.41^{\star \star}$ & $1.71,3.4$ & 0.92 & $0.61,1.39$ & 1.55 & $0.97,2.49$ & 1.12 & $0.67,1.88$ \\
\hline \multicolumn{9}{|l|}{ Ever had child: } \\
\hline Yes & $0.55^{\star \star \star}$ & $0.42,0.72$ & 0.94 & $0.71,1.26$ & $0.74^{\star}$ & $0.52,1.05$ & 0.87 & $0.6,1.25$ \\
\hline \multicolumn{9}{|l|}{ Child in household: } \\
\hline Yes & 0.98 & $0.62,1.57$ & 0.97 & $0.62,1.51$ & 1.31 & $0.8,2.14$ & 1.05 & $0.65,1.68$ \\
\hline \multicolumn{9}{|c|}{ Education level (Ref. High/post-secondary): } \\
\hline Intermediate & $1.71^{\star}$ & $1.25,2.34$ & $0.47^{\star \star \star}$ & $0.36,0.6$ & 1.25 & $0.89,1.75$ & $0.49^{\star \star \star}$ & $0.38,0.65$ \\
\hline No qualification & $2.08^{\star \star}$ & $1.55,2.8$ & $0.26^{\star \star \star}$ & $0.2,0.35$ & 1.14 & $0.82,1.6$ & $0.29^{\star \star \star}$ & $0.21,0.4$ \\
\hline \multicolumn{9}{|c|}{ Tenure status (Ref. Home-owner): } \\
\hline Mortgage & $0.8 \dagger$ & $0.6,1.06$ & 0.8 & $0.63,1.01$ & 1.16 & $0.85,1.57$ & $0.75^{\star}$ & $0.58,0.97$ \\
\hline Renting & $1.9^{\star \star}$ & $1.45,2.48$ & $0.46^{\star \star}$ & $0.33,0.65$ & 1.27 & $0.95,1.71$ & $0.67^{\star \star}$ & $0.47,0.97$ \\
\hline
\end{tabular}




\begin{tabular}{|c|c|c|c|c|c|c|c|c|}
\hline Second & $1.87^{\dagger}$ & $1.12,3.13$ & $0.77^{\star}$ & $0.57,1.03$ & 1.61 & $0.96,2.72$ & 0.88 & $0.65,1.19$ \\
\hline Third & $4.33^{\star \star}$ & $0.48,1.05$ & $0.67^{\star \star}$ & $0.49,0.91$ & $3.31^{\star \star}$ & $2.05,5.37$ & 0.84 & $0.6,1.17$ \\
\hline Fourth & $4.46^{\star \star}$ & $0.45,1.48$ & $0.47^{\star \star \star}$ & $0.33,0.66$ & $2.77^{\star}$ & $1.66,4.63$ & $0.65^{\star \star}$ & $0.44,0.96$ \\
\hline Fifth (lowest) & $6.21^{\star \star \star}$ & $0.61,1.39$ & $0.46^{\star \star \star}$ & $0.32,0.66$ & $3.36^{\star \star}$ & $1.99,5.66$ & $0.72 \dagger$ & $0.48,1.1$ \\
\hline \multicolumn{9}{|c|}{$\begin{array}{l}\text { Subjective finances (Ref. Living comfortably/ } \\
\text { doing alright): }\end{array}$} \\
\hline Difficult & $1.83^{\star \star \star}$ & $1.46,2.3$ & $0.66^{\star \star \star}$ & $0.51,0.84$ & 1.24 & $0.96,1.62$ & 1.03 & $0.77,1.37$ \\
\hline \multicolumn{9}{|c|}{ Health conditions (Ref. None): } \\
\hline Any & $1.74^{\star \star}$ & $1.32,2.3$ & 0.97 & $0.77,1.23$ & $1.38 \dagger$ & $1.01,1.89$ & 1.24 & $0.96,1.61$ \\
\hline \multicolumn{9}{|c|}{ Self-rated health (Ref. Excellent/good): } \\
\hline Fair/poor & $1.45^{\star \star}$ & $1.15,1.81$ & $0.64^{\star \star \star}$ & $0.51,0.81$ & 0.9 & $0.68,1.19$ & $0.78^{\star}$ & $0.59,1.03$ \\
\hline GHQ score & $1.03^{\star \star}$ & $1.01,1.05$ & $0.97^{\star}$ & $0.95,1$ & 1.02 & $0.99,1.04$ & 0.99 & $0.97,1.01$ \\
\hline
\end{tabular}

Notes: $\mathrm{N}=2,798$. Path 1, full-time (FT) work to low activity is the reference outcome for the multinomial logistic regression. PT: part-time. OR: odds ratio. Cl: $95 \%$ confidence interval. Ref.: reference category. GHQ: General Health Questionnaire.

Source: British Household Panel Survey Waves 6, 8, 10, 12, 14, 16 and 18.

Significance levels: $\dagger p<0.1{ }^{\star} p<0.05,{ }^{\star \star} p<0.01,{ }^{\star \star \star} p<0.001$. 
Table 5. Multinomial model of the association between activity pathways and individuals' baseline socio-demographic and health characteristics among women

\begin{tabular}{|c|c|c|c|c|c|c|c|c|}
\hline & \multicolumn{4}{|c|}{ Bivariate associations } & \multicolumn{4}{|c|}{ Multivariate model } \\
\hline & \multicolumn{2}{|c|}{$\begin{array}{l}\text { Path 1, FT work to low } \\
\text { activity }\end{array}$} & \multicolumn{2}{|c|}{$\begin{array}{c}\text { Path } 3 \text {, Multiple } \\
\text { activities }\end{array}$} & \multicolumn{2}{|c|}{$\begin{array}{l}\text { Path 1, FT work to low } \\
\text { activity }\end{array}$} & \multicolumn{2}{|c|}{$\begin{array}{c}\text { Path } 3 \text {, Multiple } \\
\text { activities }\end{array}$} \\
\hline & OR & $\mathrm{Cl}$ & OR & $\mathrm{Cl}$ & OR & $\mathrm{Cl}$ & OR & $\mathrm{Cl}$ \\
\hline \multicolumn{9}{|c|}{ Birth decade (Ref. 1940-1949): } \\
\hline $1925-1929$ & 0.8 & $0.57,1.13$ & 1.04 & $0.71,1.53$ & 1.01 & $0.7,1.46$ & 1.46 & $0.96,2.23$ \\
\hline 1930-1939 & $0.79^{\star \star}$ & $0.66,0.94$ & 1 & $0.81,1.24$ & 0.93 & $0.77,1.13$ & 1.22 & $0.96,1.55$ \\
\hline $1950-1953$ & $1.4^{\star}$ & $1.11,1.78$ & 1.13 & $0.84,1.52$ & 1.19 & $0.93,1.53$ & 0.79 & $0.58,1.09$ \\
\hline \multicolumn{9}{|c|}{ Marital status (Ref. Married or co-habiting): } \\
\hline Divorced & $2.5^{\star \star \star}$ & $2,3.13$ & $1.33 \dagger$ & $1,1.78$ & $2.6^{\star \star \star}$ & $2.03,3.32$ & $1.63^{*}$ & $1.19,2.24$ \\
\hline Widowed & $1.38^{\star}$ & $1.09,1.74$ & 1.05 & $0.79,1.4$ & $1.64^{\star \star}$ & $1.28,2.12$ & 1.21 & $0.89,1.64$ \\
\hline Never married & $2.99^{\star \star \star}$ & $2.06,4.33$ & $2.32^{\star \star}$ & $1.51,3.57$ & $3.12^{\star \star}$ & $2.01,4.83$ & $2.2^{\star}$ & $1.33,3.63$ \\
\hline \multicolumn{9}{|l|}{ Ever had child: } \\
\hline Yes & $0.73^{\star \star}$ & $0.58,0.92$ & $0.67^{\star \star \star}$ & $0.52,0.88$ & 0.94 & $0.71,1.23$ & 0.91 & $0.65,1.26$ \\
\hline \multicolumn{9}{|l|}{ Child in household: } \\
\hline Yes & 0.66 & $0.35,1.25$ & 0.92 & $0.46,1.82$ & $0.53^{\star \star}$ & $0.28,1.02$ & 0.85 & $0.39,1.85$ \\
\hline \multicolumn{9}{|c|}{ Education level (Ref. High/post-secondary): } \\
\hline Intermediate & $0.74^{\star \star}$ & $0.6,0.92$ & $0.37^{\star \star \star}$ & $0.29,0.48$ & 0.87 & $0.69,1.09$ & $0.4^{\star \star \star}$ & $0.31,0.51$ \\
\hline No qualification & $0.49^{\star \star \star}$ & $0.4,0.6$ & $0.17^{\star \star \star}$ & $0.14,0.22$ & $0.58^{\star \star \star}$ & $0.46,0.73$ & $0.2^{\star \star \star}$ & $0.15,0.26$ \\
\hline
\end{tabular}




\begin{tabular}{|c|c|c|c|c|c|c|c|c|}
\hline Mortgage & $1.51^{\star \star}$ & $1.25,1.82$ & 0.92 & $0.74,1.15$ & $1.39^{\star \star}$ & $1.14,1.7$ & 0.93 & $0.72,1.18$ \\
\hline Renting & $1.31^{\star}$ & $1.08,1.59$ & $0.53^{\star}$ & $0.41,0.69$ & $1.4^{\star}$ & $1.12,1.76$ & 0.81 & $0.6,1.08$ \\
\hline \multicolumn{9}{|c|}{ Income quintiles (Ref. First (highest)): } \\
\hline Second & $0.66^{\star \star \star}$ & $0.51,0.86$ & $0.71^{\star \star}$ & $0.53,0.94$ & $0.69^{\star \star}$ & $0.53,0.9$ & 0.82 & $0.6,1.11$ \\
\hline Third & $0.58^{\star \star \star}$ & $1,1.78$ & $0.36^{\star \star \star}$ & $0.26,0.49$ & $0.66^{\star \star \star}$ & $0.5,0.87$ & $0.49^{\star \star \star}$ & $0.34,0.69$ \\
\hline Fourth & $0.56^{\star \star \star}$ & $0.79,1.4$ & $0.46^{\star \star \star}$ & $0.35,0.62$ & $0.64^{\star \star \star}$ & $0.48,0.85$ & $0.71^{\star}$ & $0.51,0.99$ \\
\hline Fifth (lowest) & $0.54^{\star \star \star}$ & $1.51,3.57$ & $0.42^{\star \star \star}$ & $0.32,0.56$ & $0.56^{\star \star \star}$ & $0.42,0.76$ & $0.74 \dagger$ & $0.51,1.06$ \\
\hline \multicolumn{9}{|c|}{$\begin{array}{l}\text { Subjective finances (Ref. Living comfortably/ } \\
\text { doing alright): }\end{array}$} \\
\hline Difficult & 0.92 & $0.78,1.09$ & $0.58^{\star \star \star}$ & $0.47,0.72$ & 0.95 & $0.78,1.15$ & 0.89 & $0.7,1.15$ \\
\hline \multicolumn{9}{|c|}{ Health conditions (Ref. None): } \\
\hline Any & $0.79^{\star \star}$ & $0.66,0.95$ & $0.79^{\star}$ & $0.64,0.98$ & 0.86 & $0.7,1.05$ & 1.07 & $0.84,1.36$ \\
\hline \multicolumn{9}{|c|}{ Self-rated health (Ref. Excellent/good): } \\
\hline Fair/poor & $0.84^{\star}$ & $0.72,0.99$ & $0.58^{\star \star \star}$ & $0.48,0.71$ & 0.88 & $0.73,1.07$ & $0.79^{\star}$ & $0.63,1$ \\
\hline GHQ score & 1.01 & $0.99,1.02$ & $0.96^{\star \star \star}$ & $0.94,0.97$ & 1.01 & $1,1.03$ & $0.97^{\star}$ & $0.95,0.99$ \\
\hline
\end{tabular}

Notes: $\mathrm{N}=3,270$. Path 2, part-time (PT) and in-home work is the reference outcome for the multinomial logistic regression model. FT: full-time. OR: odds ratio. Cl: $95 \%$ confidence interval. Ref.: reference category. GHQ: General Health Questionnaire.

Source: British Household Panel Survey Waves 6, 8, 10, 12, 14, 16 and 18 .

Significance levels: $\dagger p<0.1{ }^{\star} p<0.05,{ }^{\star \star} p<0.01,{ }^{\star \star \star} p<0.001$. 
$1.51,3.57)$ than in the PT and in-home work pathway. These effects became somewhat stronger in the multivariate models after controlling for demographic and socio-economic characteristics (Table 5). Differences according to parenthood were also observed, as mothers were less likely to follow the FT work to low activity and the multiple activities pathways according to the bivariate models. In the multivariate model, having a child in the household at baseline reduced the likelihood of being in the FT work to low activity pathway rather than the PT and in-home work pathway. Lower education was associated with being in the PT and in-home work pathway, as having no qualifications decreased the odds of being in the FT work to low activity and the multiple activities pathways $(\mathrm{OR}=0.49, \mathrm{CI}=0.4,0.6$ and $\mathrm{OR}=$ $0.17, \mathrm{CI}=0.14,0.22$, respectively). Being in a lower income quintile was also associated with lower odds of being in these two pathways among women. However, mortgage holders $(\mathrm{OR}=1.51, \mathrm{CI}=1.25,1.82)$ and renters $(\mathrm{OR}=1.31, \mathrm{CI}=1.08$, 1.59) were instead more likely to belong to the FT work to low activity group than outright home-owners. Renters were less likely to be characterised by the multiple activities pathway $(\mathrm{OR}=0.53, \mathrm{CI}=0.41,0.69)$, though the effect was attenuated in the multivariate model after controlling for other socio-economic characteristics. Better health raised the odds of being in the FT work to low activity and the multiple activities pathways among women, though this effect was nonsignificant in the multivariate model for the FT work to low activity pathway after controlling for socio-economic variables. Reporting worse self-rated health and suffering from a chronic health problem were associated with higher odds of being in the PT and in-home work pathway. Worse GHQ scores decreased the odds of being in the multiple activities pathway $(\mathrm{OR}=0.96, \mathrm{CI}=0.94,0.97)$.

Results from the multinomial logistic models showed that activity pathways were related to socio-demographic and health characteristics. While there were marked gender differences in the composition of the pathways, broadly similar associations between these and individual characteristics were observed among men and women. Being classified in the PT and in-home work pathway was generally associated with being less socio-economically advantaged, and having worse health. By contrast, being in the multiple activities pathway was associated with having higher socio-economic conditions and better health.

\section{Discussion}

Using seven waves of data collected between 1996 and 2008 in the UK, we examined how distinct sub-groups of individuals combine participation in paid and unpaid activities over time in the years proceeding and following the UK State Pension ages. We identified three distinct activity pathways in paid and unpaid work which captured the heterogeneity of individuals' participation in multiple activities as they progressed through mid to later life. The FT work to low activity pathway was characterised by a higher probability of full-time paid work and lower probability of participation in all unpaid activities and part-time paid work. The $P T$ and in-home work pathway was characterised by a lower probability of full-time paid work, and a substantially higher probability of working part-time, doing housework and providing co-residential informal care relative to the first pathway. The multiple activities pathway showed a substantially higher probability of 
engaging in volunteering and civic participation relative to the other two pathways. Within each pathway, the declining probability of participating in the paid labour market was not paralleled by increases in the probability of engaging in unpaid forms of work (neither role substitution nor extension); the only exception being the slight increase in the probability of volunteering and civic participation in the FT work to low activity and the PT and in-home work pathway. Therefore, those in the multiple activities pathway who were most likely to take part in unpaid forms of work between the ages of 55 and 70 were more likely to do so already at ages 55-56; and the probability remained mostly constant throughout this period.

Despite the stark differences in the extent of involvement in unpaid work across the pathways, our findings corroborate neither the role substitution nor extension hypotheses (Mutchler et al., 2003). The declining participation in paid work observed in all pathways is not paralleled by either increasing or decreasing participation in unpaid activities. The difference in the extent of involvement in unpaid activities across the pathways appears to result from continuities in unpaid activities during the period observed, as certain individuals were continuously more likely to engage in unpaid activities. Our findings, which indicate stability in patterns of unpaid activities over 15 years in mid to later life within latent groups, corroborate with previous research showing state dependence in unpaid activities in later life (Di Gessa and Grundy, 2017; Vangen et al., 2021).

A putative explanation for differences across the latent pathways is that they reflect the selection of individuals due to earlier variations in lifecourse patterns of activities, which could not be observed in our study as we first observe people at age 55. For instance, prior lifecourses characterised by higher participation in unpaid activities and lower attachment to full-time employment may have continued into later life, shaping the patterns of activities observed in the PT and in-home work and multiple activities pathways. Previous evidence shows this selection mechanism can account for variations in paid work, as people who had higher attachment to the paid labour market earlier in life were found to be more likely to participate in paid work in later life (Pienta et al., 1994; Finch, 2014; Di Gessa et al., 2017). Selection earlier in the lifecourse could be relevant also for unpaid forms of work, whereby individuals who were more 'attached' to unpaid activities earlier in their lifecourse are more likely to participate in these same activities in later life (Young and Grundy, 2008; Lancee and Radl, 2014). While we could not examine participation in unpaid activities earlier in the lifecourse as data on volunteering, civic participation and housework is not available in the BHPS, future research using longer follow-up periods could examine how participation in multiple paid and unpaid activities develops over the lifecourse and its impact on outcomes in later life, such as health (Stone et al., 2015; Lu et al., 2017).

Our results identified fewer sub-groups than previous studies that have examined latent patterns of activities using similar person-centred approaches in crosssectional analyses. However, while the pathways shown herein may seem considerably different from those identified in previous studies, this is because we examined the issue longitudinally. Results from the first-stage cross-sectional LCA (see Tables A.1a and A.1b in the online supplementary material) share several similarities with previous cross-sectional evidence. The large full-time paid work-oriented subgroups (class 4 at ages 55-56; class 2 at 57-58; class 3 at 59-60; class 4 at $61-$ 
62) resemble the 'working' sub-group identified by Morrow-Howell et al. (2014) in their overall activity patterns. The sub-groups with a moderate probability of fulltime paid work and a high probability of volunteering and civic participation (class 3 at ages 55-56; class 1 at 57-58; class 1 at 59-60; class 1 at 61-62) closely resemble the 'workers/volunteers' group identified by Burr et al. (2007). The sub-groups with low probability of paid work and a high probability of all unpaid activities (class 2 at ages 55-56; class 3 at ages 57-58; class 3 at ages 61-62) resemble the 'superhelpers', 'high activity' and the 'family-helpers' groups identified in the studies by Burr et al. (2007), Morrow-Howell et al. (2014) and Mergenthaler et al. (2019), respectively. Differences with previous cross-sectional studies reflect the longitudinal approach taken here, whereby the age-related effects were modelled explicitly in the two-staged LCA. For example, Burr et al. (2007) reported that clusters of activities were related to age, and that this could reflect individuals reducing their participation in unpaid activities, supporting the selective optimisation with compensation theory. Our findings instead highlight the importance of differences between individuals rather than age differences, as the probability of engaging in unpaid activities is mostly constant over time within each pathway. Future research should consider the effect of age on activities in a longitudinal perspective, as age differences might reflect mechanisms that are only correlated with age, e.g. declining health, retirement from paid work, and cohort and period effects.

Our findings show that paid and unpaid activities are socially patterned, suggesting that not all social groups may have similar opportunities to engage in various activities at these ages. This corroborates previous studies that showed similar patterns (Morrow-Howell et al., 2014). Individuals classified in the PT and in-home work pathway generally showed lower socio-economic status and poorer health. By contrast, individuals classified in the multiple activities sub-group tend to have higher socio-economic status and better health. Women in the FT work to low activity pathway were significantly more likely to live in rented housing or have a mortgage than to be outright home-owners, indicating that having to pay rent or a mortgage may make working in full-time paid work in mid to later life a necessity. This is in agreement with previous research suggesting that individuals who have household debts or mortgages may need to remain in paid work for longer (Lain, 2015; Scherger, 2015). Overall, findings partially support what we expected according to cumulative inequality. Circumstances of relative disadvantage may compound for individuals in the PT and in-home work pathway, as they are more likely to have lower socio-economic position and worse health at baseline, and they are more likely to engage in non-discretionary unpaid activities (housework and care-giving). The lower health status may act as a barrier to working longer, as people who work past retirement ages are more likely to have better prior health (Di Gessa et al., 2017). Similarly, health and care-giving may act as barriers for health-enhancing activities, such as volunteering ( $\mathrm{Li}$ and Ferraro, 2006). By contrast, the higher socio-economic position and better health of individuals in the multiple activities pathway may facilitate their choices regarding participation in paid and unpaid activities in later life. Higher income and home-ownership can provide financial security, enabling more control over when and whether they wish to retire from the paid labour market, as well as opening possibilities to employ others to undertake care and household work. 
As participation in paid and unpaid work is conspicuously gendered, the three latent pathways reflect the traditional 'male breadwinner' model in these cohorts, as women are substantially more likely to engage in unpaid forms of work, while men are more likely to work in full-time employment. This gendered division may persist among older cohorts as the institution of the welfare state in the UK favoured single-earner families in the post-Second World War period (Creighton, 1999). Results from the multinomial models also support the persistence of the traditional division of labour in the UK as a 'modified male breadwinner family' arrangement, whereby married women are more likely to work part-time and have lower attachment to full-time employment, while men are more likely to work full-time continuously throughout their lifecourse (Loretto and Vickerstaff, 2012). Previous research has shown that this arrangement affects workforce participation in later life (van der Horst et al., 2017a, 2017b). Our findings show that the 'modified male breadwinner family' model affects overall involvement in paid and unpaid activities in mid to later life, as marital status is particularly important in determining women's activity patterns. Furthermore, parenthood lowers men's likelihood of being in the PT and in-home work pathway, while it is the opposite for women, indicating how child care reinforces the persistence of the gendered division of labour. Overall, our results emphasise that retirement may have different meanings for men and women's involvement in paid and unpaid activities (Loretto and Vickerstaff, 2012).

\section{Limitations and future research}

Our findings contribute to previous research by showing a nuanced picture of the diversity of patterns of paid and unpaid activities, and how these are connected to individual socio-demographic and health characteristics. However, the study has some limitations. First, the relationships shown in the multinomial models do not allow for causal inference, due to reverse causality and selection mechanisms, as covariates were measured only at baseline. Nevertheless, findings provide novel evidence regarding how socio-economic factors and health are associated with patterns of paid and unpaid activities in later life, consistent with the idea of cumulative inequality. Second, our findings are specific to the UK and the cohorts included in this sample, and cannot be readily generalised to future cohorts or other national contexts. As mentioned above, the cohorts analysed here lived in a welfare state and culture that incentivised single-earner families. The interplay between paid and unpaid activities may have changed, as more women have joined the paid labour force among younger cohorts and wider societal changes have affected participation in activities in later life (e.g. changes in retirement age, availability of the internet). Third, role theory, which was used as this study's guiding theoretical framework, has been critiqued for its failure to take human agency into account adequately, i.e. the subjective experiences of an individuals' involvement in an activity rather than just the occupation of a 'role' (Jackson, 1998). While we observed participants' reported activities, it was not possible to assess whether their activities matched their intentions or resulted from external constraints. Information on individuals' motivations and opportunities for taking part in activities is required to contextualise participants' behaviours better with respect to the roles they occupy. For instance, knowing whether a respondent wishes to volunteer, to retire, and whether there is a demand for family care 
would enable a better assessment of the motivations underlying reported behaviours. Nevertheless, by combining role theory with cumulative inequality we were able to examine possible role conflicts and whether these are unequally distributed according to individual characteristics. Fourth, only binary measures for civic participation and volunteering were used in order to preserve the parsimony of the LCA models, as convergence for first-stage models was susceptible to categories with low numbers. Finally, missing data and attrition may have affected the sample composition, as is the case for any long unbalanced panel. Nevertheless, FIML was used as the estimation procedure for all models, which allows the use of all available data, with the lessrestrictive MAR assumption (Allison, 2012).

\section{Conclusion}

This study extends previous research by exploring patterns of multiple paid and unpaid activities longitudinally. Overall, the findings suggest that individuals who work in full-time employment for longer have a lower probability of participating in unpaid activities even after ceasing paid employment. Consequently, policies that aim to extend working lives and promote active ageing should consider the different levels of involvement in unpaid activities of different segments of the population. Activity pathways are highly gendered and related to socio-economic and health characteristics. These findings emphasise the importance of considering gender, socio-economic and health inequalities in relation to the prospect of longer working lives and active ageing. Active ageing-related initiatives may risk excluding those in worse health and with lower socio-economic position, as individuals in the multiple activities pathway arguably were the only ones that reached the active ageing ideal of partaking in several activities, including health-enhancing ones such as volunteering. Extending working lives may further disadvantage individuals grouped in the PT and in-home work pathway, who are more likely to be in worse health and have fewer socio-economic resources, while at the same time depending financially on paid work given a higher likelihood of having low incomes and being renters.

Findings are specific to the particular period under consideration (1996-2008) and wider societal changes will likely affect successive cohorts' patterns of paid and unpaid activities. For instance, the spread of the internet may enhance individuals' access to opportunities for civic participation and volunteering. However, digital exclusion among older adults and disadvantaged groups may mean that socio-economic inequalities in paid and unpaid activities are exacerbated, as internet use varies between cohorts, and according to health and financial circumstances (Matthews et al., 2019). Furthermore, older adults' labour force participation may be affected by the postponement of the State Pension age in the UK, which has increased sharply, especially for women. The need to remain in the labour market for longer may raise the conflict between paid work and informal care (Carrino et al., 2019). The COVID-19 pandemic and economic downturns are also factors that have affected older adults' paid and unpaid work, potentially by reducing opportunities for paid work, while increasing the load for informal carers and dampening participation in volunteering (Lim and Laurence, 2015; Chatzi et al., 2020). 
Policies should avoid taking a blanket approach to extending working lives, and instead recognise the heterogeneity of individuals' circumstances. For instance, disadvantaged individuals may not have the same access to work environments that facilitate the inclusion of older people or that enable the combination of paid and unpaid activities, e.g. non-strenuous employment and flexible working arrangements. The promotion of paid and unpaid activities in later life may only benefit individuals who have advantaged circumstances, such as higher income, higher education and better health, as they are more likely to have favourable and flexible working conditions and greater decision latitude with respect to the timing of their retirement (Gonzales et al., 2015). It is also critical that policies recognise the unpaid work of informal care-givers, given that this is a non-discretionary and unplanned activity that may lead individuals to exit the labour market (Carr et al., 2018) and face financial disadvantage (Evandrou and Glaser, 2003; Heitmueller and Inglis, 2007). Since providing informal care is most prevalent in mid to later life (Dahlberg et al., 2007; Verbakel et al., 2017), policies that support informal carers would benefit older adult themselves as well as society at large (Pickard, 2019).

Supplementary material. The supplementary material for this article can be found at https://doi.org/10. 1017/S0144686X21001537

Acknowledgements. Data from the British Household Panel Survey were obtained through the UK Data Service. Neither the original collectors of the data nor the Archive bear any responsibility for the analysis or interpretations presented here. We would like to thank Loretta G. Platts for feedback and discussions on a draft of this paper. We would like to express our gratitude to the members and moderator of the workshop for PhD students, 'Life-course Influences on Retirement: Researchers' and Stakeholders' Perspectives' which took place at Helsinki University, who provided valuable feedback on an early draft of this paper.

\section{Author contributions.}

LBS designed and carried out the research and was primary author for the manuscript; LMC, DP and KG provided supervision, feedback and critical revisions to the manuscripts. LMC provided guidance on the study design, data analysis and interpretation of the two-staged latent class analysis.

Financial support. This work was supported by the British cross-research council Lifelong Health and Wellbeing (LLHW) programme under Extending Working Lives as part of an inter-disciplinary consortium on Wellbeing, Health, Retirement and the Lifecourse (WHERL) (grant number ES/L002825/1); and the Kamprad Family Foundation (LBS, grant number 20180313).

Conflict of interest. The authors declare no conflicts of interest.

Ethical standards. Ethical approval was not required for this paper. British Household Panel Survey data were accessed and analysed in compliance with terms provided by the UK Data Service.

\section{References}

Allison PD (2012) Handling missing data by maximum likelihood (No. 312). Paper presented at the SAS Global Forum, April 2012: Statistics and Data Analysis, Orlando, FL. https://support.sas.com/resources/ papers/proceedings $12 /$.

Arpino B and Bordone V (2018) Active ageing typologies: a latent class analysis of the older Europeans. In Zaidi A, Harper S, Howse K, Lamura G and Perek-Białas J (eds), Building Evidence for Active Ageing Policies. Singapore: Palgrave Macmillan, pp. 295-311.

Asparouhov T and Muthén BO (2012) Using Mplus TECH11 and TECH14 to test the number of latent classes. Mplus Web Notes No. 14. May 22, 2012. 
Boudiny K (2013) 'Active ageing': from empty rhetoric to effective policy tool. Ageing \& Society 33, 1077-1098.

Burr JA, Choi NG, Mutchler JE and Caro FG (2005) Caregiving and volunteering: are private and public helping behaviors linked? Journals of Gerontology: Psychological Sciences and Social Sciences 60B, S247-S256.

Burr JA, Mutchler JE and Caro FG (2007) Productive activity clusters among middle-aged and older adults: intersecting forms and time commitments. Journals of Gerontology: Psychological Sciences and Social Sciences 62B, S267-S275.

Calvo E, Madero-Cabib I and Staudinger UM (2017) Retirement sequences of older Americans: moderately destandardized and highly stratified across gender, class, and race. The Gerontologist 14, 28-39.

Caro FG and Bass SA (1997) Receptivity to volunteering in the immediate postretirement period. Journal of Applied Gerontology 16, 427-441.

Carr DC and Kail BL (2012) The influence of unpaid work on the transition out of full-time paid work. The Gerontologist 53, 92-101.

Carr E, Murray ET, Zaninotto P, Cadar D, Head J, Stansfeld S and Stafford M (2018) The association between informal caregiving and exit from employment among older workers: prospective findings from the UK Household Longitudinal Study. Journals of Gerontology: Psychological Sciences and Social Sciences 73B, 1253-1262.

Carrino L, Nafilyan VL and Avendano M (2019) Should I Care or Should I Work? The Impact of Working in Older Age on Caregiving. York, UK: HEDG, Department of Economics, University of York.

Chambré SM (1984) Is volunteering a substitute for role loss in old age? An empirical test of activity theory. The Gerontologist 24, 292-298.

Chatzi G, Di Gessa G and Nazroo JY (2020) Changes in Older People's Experiences of Providing Care and of Volunteering During the COVID-19 Pandemic. London: English Longitudinal Study of Ageing. Available at https://www.elsa-project.ac.uk/covid-19-reports.

Choi LH (2003) Factors affecting volunteerism among older adults. Journal of Applied Gerontology 22, 179-196.

Choi NG, Burr JA, Mutchler JE and Caro FG (2007) Formal and informal volunteer activity and spousal caregiving among older adults. Research on Aging 29, 99-124.

Corna LM and Sacker A (2013) A lifetime of experience: modeling the labour market and family histories of older adults in Britain. Longitudinal and Life Course Studies 4, 33-56.

Creighton C (1999) The rise and decline of the 'male breadwinner family' in Britain. Cambridge Journal of Economics 23, 519-541.

Dahlberg L, Demack S and Bambra C (2007) Age and gender of informal carers: a population-based study in the UK. Health \& Social Care in the Community 15, 439-445.

Dentinger E and Clarkberg M (2002) Informal caregiving and retirement timing among men and women. Journal of Family Issues 23, 857-879.

Di Gessa G and Grundy E (2017) The dynamics of paid and unpaid activities among people aged 50-69 in Denmark, France, Italy, and England. Research on Aging 39, 1013-1038.

Di Gessa G, Corna LM, Platts LG, Worts D, McDonough P, Sacker A, Price D and Glaser K (2017) Is being in paid work beyond state pension age beneficial for health? Evidence from England using a lifecourse approach. Journal of Epidemiology and Community Health 71, 431-438.

Dosman D, Fast J, Chapman SA and Keating N (2006) Retirement and productive activity in later life. Journal of Family and Economic Issues 27, 401-419.

Dury S, De Donder L, De Witte N, Brosens D, Smetcoren A-S, Van Regenmortel S and Verté D (2016) Is volunteering in later life impeded or stimulated by other activities? Research on Aging 38, 51-75.

Evandrou M and Glaser K (2003) Combining work and family life: the pension penalty of caring. Ageing \& Society 23, 583-601.

Fasang AE (2010) Retirement: institutional pathways and individual trajectories in Britain and Germany. Sociological Research Online 15, 1-16.

Fast JE, Dosman D and Moran L (2006) Productive activity in later life. Research on Aging 28, 691-712.

Fernandez-Ballesteros R, Zamarron MD, Diez-Nicolas J, Lopez-Bravo MD, Molina MA and Schettini R (2011) Productivity in old age. Research on Aging 33, 205-226.

Ferraro KF and Shippee TP (2009) Aging and cumulative inequality: how does inequality get under the skin? The Gerontologist 49, 333-343. 
Finch N (2014) Why are women more likely than men to extend paid work? The impact of work-family life history. European Journal of Ageing 11, 31-39.

Foster L and Walker A (2015) Active and successful aging: a European policy perspective. The Gerontologist 55, 83-90.

Glaser K, Evandrou M and Tomassini C (2006) Multiple role occupancy and social participation among midlife wives and husbands in the United Kingdom. International Journal of Aging and Human Development 63, 27-47.

Goldberg DP and Williams P (1988) A User's Guide to the GHQ. Windsor, UK: NFER-Nelson.

Gonzales E, Matz-Costa C and Morrow-Howell N (2015) Increasing opportunities for the productive engagement of older adults: a response to population aging. The Gerontologist 55, 252-261.

Goode WJ (1960) A theory of role strain. American Sociological Review 25, 483-496.

Hank K and Erlinghagen M (2009) Dynamics of volunteering in older Europeans. The Gerontologist 50, $170-178$.

Hank K and Stuck S (2008) Volunteer work, informal help, and care among the 50+ in Europe: further evidence for 'linked' productive activities at older ages. Social Science Research 37, 1280-1291.

Heitmueller A and Inglis K (2007) The earnings of informal carers: wage differentials and opportunity costs. Journal of Health Economics 26, 821-841.

Henz U (2004) The effects of informal care on paid-work participation in Great Britain: a lifecourse perspective. Ageing \& Society 24, 851-880.

Herzog AR and Morgan JN (1993) Formal volunteer work among older Americans. In Bass SA, Caro FG and Chen Y-P (eds), Achieving a Productive Aging Society. Westport, CT: Auburn House, pp. 119-142.

Jackson J (1998) Contemporary criticisms of role theory. Journal of Occupational Science 5, 49-55.

Jacobs JC, Laporte A, Van Houtven CH and Coyte PC (2014) Caregiving intensity and retirement status in Canada. Social Science \& Medicine 102, 74-82.

Kelle N (2020) Combining employment and care-giving: how differing care intensities influence employment patterns among middle-aged women in Germany. Ageing \& Society 40, 925-943.

Kobayashi E, Sugihara Y, Fukaya T and Liang J (2019) Volunteering among Japanese older adults: how are hours of paid work and unpaid work for family associated with volunteer participation? Ageing \& Society 39, 2420-2442.

Lain D (2015) Work beyond age 65 in England and the USA. In Scherger S (ed.), Paid Work Beyond Pension Age. London: Palgrave Macmillan, pp. 31-56.

Lancee B and Radl J (2014) Volunteering over the life course. Social Forces 93, 833-862.

Levy H and Jenkins S (2012) Documentation for Derived Current and Annual Net Household Income Variables, BHPS Waves 1-18 (UK Data Archive Study 3909). Colchester, UK: Institute for Social and Economic Research.

Li Y and Ferraro KF (2006) Volunteering in middle and later life: is health a benefit, barrier or both? Social Forces 85, 497-519.

Lim C and Laurence J (2015) Doing good when times are bad: volunteering behaviour in economic hard times. British Journal of Sociology 66, 319-344.

Loretto W and Vickerstaff S (2012) The domestic and gendered context for retirement. Human Relations 66, 65-86.

Lu W, Benson R, Glaser K, Platts LG, Corna LM, Worts D, McDonough P, Di Gessa G, Price D and Sacker A (2017) Relationship between employment histories and frailty trajectories in later life: evidence from the English Longitudinal Study of Ageing. Journal of Epidemiology \& Community Health 71, 439-445.

Macmillan R and Eliason SR (2003) Characterizing the life course as role configurations and pathways. In Mortimer JT and Shanahan MJ (eds), Handbook of the Life Course. Boston, MA: Springer, pp. 529-554.

Matthews K, Nazroo J and Marshall A (2019) Digital inclusion in later life: cohort changes in internet use over a ten-year period in England. Ageing \& Society 39, 1914-1932.

Mergenthaler A, Sackreuther I and Staudinger UM (2019) Productive activity patterns among 6070-year-old retirees in Germany. Ageing \& Society 39, 1122-1151.

Michaud PC, Heitmueller A and Nazarov Z (2010) A dynamic analysis of informal care and employment in England. Labour Economics 17, 455-465.

Moen P (2003) Midcourse: navigating retirement and a new life stage. In Mortimer JT and Shanahan MJ (eds), Handbook of the Life Course. Boston, MA: Springer, pp. 269-291. 
Morrow-Howell N, Putnam M, Lee YS, Greenfield JC, Inoue M and Chen H (2014) An investigation of activity profiles of older adults. Journals of Gerontology: Psychological Sciences and Social Sciences 69B, 809-821.

Mutchler JE, Burr JA and Caro FG (2003) From paid worker to volunteer: leaving the paid workforce and volunteering in later life. Social Forces 81, 1267-1293.

Muthén BO and Muthén LK (2012) Mplus 7 Base Program. Los Angeles, CA: Muthén \& Muthén.

O'Rand AM (1996) The precious and the precocious: understanding cumulative disadvantage and cumulative advantage over the life course. The Gerontologist 36, 230-238.

Parsons T (1951) The major points of reference and structural components of the social system. In The Social System. London: Routledge, pp. 24-67.

Pickard L (2019) Good value for money? Public investment in 'replacement care' for working carers in England. Social Policy and Society 18, 365-382.

Pienta AM, Burr JA and Mutchler JE (1994) Women's labor force participation in later life: the effects of early work and family experiences. Journal of Gerontology 49, S231-S239.

Scherger S (2015) Introduction: Paid work beyond pension age-causes, contexts, consequences. In Scherger S (ed.), Paid Work Beyond Pension Age. London: Palgrave Macmillan, pp. 1-27.

Sieber SD (1974) Toward a theory of role accumulation. American Sociological Review 39, 567-578.

StataCorp (2017) Stata Statistical Software: Release 15. College Station, TX: StataCorp.

Stone J, Evandrou M, Falkingham J and Vlachantoni A (2015) Women's economic activity trajectories over the life course: implications for the self-rated health of women aged 64+ in England. Journal of Epidemiology \& Community Health 69, 873-879.

Strauss S (2021) Multiple engagement: the relationship between informal care-giving and formal volunteering among Europe's 50+ population. Ageing \& Society 41, 1562-1586.

Taylor MF (2010) British Household Panel Survey User Manual Volume A: Introduction, Technical Report and Appendices. Colchester, UK: University of Essex, Institute for Social and Economic Research.

Tein J-Y, Coxe S and Cham H (2013) Statistical power to detect the correct number of classes in latent profile analysis. Structural Equation Modeling: A Multidisciplinary Journal 20, 640-657.

University of Essex, Institute for Social and Economic Research (2018) British Household Panel Survey: Waves 1-18, 1991-2009, [data collection]. 8th Edition. UK Data Service. SN: 5151, http://doi.org/10. 5255/UKDA-SN-5151-2.

van den Bogaard L, Henkens K and Kalmijn M (2014) So now what? Effects of retirement on civic engagement. Ageing \& Society 34, 1170-1192.

van der Horst M, Lain D, Vickerstaff S, Clark C and Baumberg Geiger B (2017a) Gender roles and employment pathways of older women and men in England. SAGE Open 7. Available at https://doi. org/10.1177/2158244017742690.

van der Horst M, Vickerstaff S, Lain D, Clark C and Baumberg Geiger B (2017b) Pathways of paid work, care provision, and volunteering in later careers: activity substitution or extension? Work, Aging and Retirement 3, 343-365.

Vangen H, Hellevik T and Herlofson K (2021) Associations between paid and unpaid work among Norwegian seniors: competition, complementarity or continuity? European Journal of Ageing. https:// doi.org/10.1007/s10433-021-00615-9.

Verbakel E, Tamlagsrønning S, Winstone L, Fjær EL and Eikemo TA (2017) Informal care in Europe: findings from the European Social Survey (2014) special module on the social determinants of health. European Journal of Public Health 27, 90-95.

Vickerstaff S and Cox J (2005) Retirement and risk: the individualisation of retirement experiences? The Sociological Review 53, 77-95.

Wilson J (2000) Volunteering. Annual Review of Sociology 26, 215-240.

World Health Organization (2002) Active Ageing: A Policy Framework. Geneva: World Health Organization.

Young H and Grundy E (2008) Longitudinal perspectives on caregiving, employment history and marital status in midlife in England and Wales. Health \& Social Care in the Community 16, 388-399.

Cite this article: Sacco LB, Corna LM, Price D, Glaser K (2021). Pathways of participation in paid and unpaid work in mid to later life in the United Kingdom. Ageing \& Society 1-28. https://doi.org/10.1017/ S0144686X21001537 